\title{
BMJ Open Predictive and spatial analysis for estimating the impact of sociodemographic factors on contraceptive use among women living with HIV/AIDS (WLWHA) in Kenya: Implications for policies and practice
}

\author{
Menkeoma Laura Okoli, ${ }^{1}$ Samuel Alao, ${ }^{2}$ Somtochukwu Ojukwu, \\ Nnadozie C Emechebe, ${ }^{1}$ Asuelimen Ikhuoria, ${ }^{3}$ Kevin E Kip ${ }^{1}$
}

To cite: Okoli ML, Alao S, 0jukwu S, et al. Predictive and spatial analysis for estimating the impact of sociodemographic factors on contraceptive use among women living with HIV/AIDS (WLWHA) in Kenya: Implications for policies and practice. BMJ Open 2019;9:e022221. doi:10.1136/ bmjopen-2018-022221

- Prepublication history and additional material for this paper are available online. To view these files, please visit the journal online (http://dx.doi. org/10.1136/bmjopen-2018022221).

Received 20 June 2018 Revised 24 November 2018 Accepted 27 November 2018

Check for updates

(C) Author(s) (or their employer(s)) 2019. Re-use permitted under CC BY-NC. No commercial re-use. See rights and permissions. Published by BMJ.

For numbered affiliations see end of article.

Correspondence to Dr Menkeoma Laura Okoli; lauraokoli@health.usf.edu

\section{ABSTRACT}

Background Despite the availability and knowledge of various contraceptive methods, consistent utilisation in women living with HIV/AIDS (WLWHA) within the reproductive age group remains below the Sustainable Development Goals (SDGs) and Family Planning 2020 goals. This study examines the association between sociodemographic factors and contraceptive use including the effect of clustering tendencies of these factors on contraceptive usage among WLWHA in Kenya.

Methods Weighted multivariate logistic regression models were conducted to determine the association of sociodemographic factors on contraception use among WLWHA using the 2008-2009 Kenya Demographic Health Survey. Spatial autocorrelation techniques were used to explore clustering tendencies of these factors on contraception utilisation. Our study population included 304 HIV positive women, aged 15-49 years.

Results Among 304 HIV-positive women in our study population, $92(30.3 \%)$ reported using one method of contraception. Contraceptive use was significantly associated with wealth and education after adjustment for other sociodemographic variables. Women classified as having low and middle wealth index were less likely to use contraceptives $(0 \mathrm{R}=0.17$, $95 \% \mathrm{Cl} 0.07$ to 0.43 ; $0 \mathrm{R}=0.33,95 \% \mathrm{Cl} 0.11$ to 0.98 , respectively) compared with women classified as having high wealth index. Similarly, women with primary education only were less likely to use contraceptives compared with women with secondary or higher education ( $\mathrm{OR}=0.42,95 \% \mathrm{Cl} 0.18$ to 0.98$)$. Spatial autocorrelation revealed significant positive clusters with weak clustering tendencies of noncontraceptive use among different levels of wealth index and education within different regions of Kenya. Conclusion These findings underscores the need for intervention programmes to further target socially disadvantaged WLWHA, which is necessary for achieving the SDGs.

\section{Strengths and limitations of this study}

- To the best of our knowledge, this is the first study to explore both statistical and spatial analysis of the impact of sociodemographic factors on contraceptive use among women Living with HIV/AIDS (WLWHA), especially WLWHA in Kenya.

- The Demographic Health Surveys (DHS 2008-2009) data used in this study represents nationally representative data that enhances generalisability of results.

- Despite the use of nationally representative data, the study design was cross-sectional and limits our ability to make causal inferences due to the inability to ascertain the direction of causality.

- Furthermore, data collected were based on self-report and could be prone to recall and social desirability bias.

\section{INTRODUCTION}

$\mathrm{HIV} / \mathrm{AIDS}$ is a pandemic disease with devastating socioeconomic effects on the world's population. Globally, about 35 million people were reported to be living with HIV/ AIDS (PLWHA) in 2013. Sub-Saharan Africa accounts for $70 \%$ of the HIV burden worldwide. ${ }^{12}$ In East Africa, Kenya has the highest HIV burden with a prevalence rate of $6 \%$, and majority of these cases have been attributed to unsafe sexual practices. ${ }^{1}$ Kenya has a record of 1.5 million PLWHA with 36000 AIDS-related deaths in 2015; in addition, women within the reproductive age group of 15-49 years account for more than $50 \%$ of cases. ${ }^{3-5}$ The number of AIDS-related deaths in Kenya have progressively reduced by $32 \%$ from 2005 to 2013 due to improved access to antiretroviral therapy. ${ }^{1}$ Despite the advances in the 
management of HIV/AIDS, substantial gaps exist in relation to the reproductive needs of women living with HIV/ AIDS (WLWHA), particularly in accessibility and use of contraceptives. ${ }^{4}$

From a public health perspective, contraceptive use in WLWHA can directly impact a range of health conditions including prevention of unplanned pregnancies and abortions, prevention of mother-to-child transmission (PMTCT), reduction in sexually transmitted infections, decline in maternal deaths during pregnancies, reduction of HIV superinfection (infection with a different strain of HIV) and reduction in chances of HIV transmission to their uninfected partner. ${ }^{6}$ Therefore, addressing the reproductive health needs of WLWHA is critical to prevent unplanned pregnancy and to promote maternal and child health, a component of PMTCT action point as stated by the WHO, which has been shown to be more cost-effective than treatment of HIV positive mothers and babies with antiretroviral therapy. ${ }^{246-9}$

The Spectrum and Estimation and Projection Package (EPP) has been used in Kenya to model adult HIV infection rate, maternal-to-child transmission, child survival and maternal AIDS deaths in determining HIV prevalence. Despite this important contribution, there are gaps in the outputs generated from EPP models regarding estimates of HIV indicators at the district level due to plausible global incidence data and uncertainty in key assumptions employed in the model. ${ }^{10}$ Whereas the EPP model can project trends of HIV indicators and serve as a potent biosurveillance tool to monitor epidemic, it does not possess geographic information systems (GIS) mapping capabilities for determining HIV indices-related clusters.

Given the limited resources in Kenya, GIS is a valuable tool in providing insights into proximity analysis, disease clustering tendencies, identification of hotspots and performing spatiotemporal regression analysis that can improve the efficiency of distributing scarce resources to problematic hotspots. In a similar realm, some studies have employed the application of GIS and remote sensing techniques on georeferenced, normalised and spatiotemporal HIV-related datasets in analysing proximity geographic centroids to health facilities and other barriers to accessing health services in low-resource countries. ${ }^{11-16}$ This study adds to the existing evidence base on the use of spatial analysis in HIV-related topics and uniquely identifies how clustering tendencies of sociodemographic factors alone or in combination affect contraceptive use among WLWHA, in particular, WLWHA in Kenya.

Therefore, the aims of this study were to: (1) investigate and quantify the relationship between sociodemographic factors and contraceptive use among WLWHA in Kenya and (2) create a robust model to identify clustering tendencies of sociodemographic factors on contraceptive use among WLWHA using spatial autocorrelation techniques, hotspot and cluster analysis.

\section{METHODS}

\section{Study design and data source}

This cross-sectional study used data from the 20082009 Kenya Demographic Health Survey (KDHS). ${ }^{17}$

Table 1 Characteristics of HIV-positive women by contraceptive use in Kenya (DHS 2008-2009)

\begin{tabular}{|c|c|c|c|c|}
\hline & Total & Using & Not using & \\
\hline & $(n=304)$ & $(n=92)$ & $(n=212)$ & \\
\hline Variables & N (\%) & N (\%) & $\mathrm{N}(\%)$ & $P$ value \\
\hline Region & & & & 0.2088 \\
\hline Nairobi & $36(10.8)$ & 14 (17.9) & $22(7.9)$ & \\
\hline Coast & $29(5.4)$ & $9(3.3)$ & $20(6.2)$ & \\
\hline Nyanza & $118(35.3)$ & $34(35.7)$ & $84(35.1)$ & \\
\hline Rift Valley & $29(20.0)$ & $9(15.8)$ & $20(21.7)$ & \\
\hline Western & $46(12.5)$ & $9(7.8)$ & $37(14.4)$ & \\
\hline Others & 46 (15.9) & 17 (19.5) & $29(14.5)$ & \\
\hline Residence & & & & 0.132 \\
\hline Urban & $112(29.6)$ & 42 (38.9) & $70(25.9)$ & \\
\hline Rural & $192(70.4)$ & $50(61.1)$ & $142(74.1)$ & \\
\hline Ethnicity & & & & 0.2536 \\
\hline Kikuyu & 38 (13.9) & 17 (18.4) & 21 (12.0) & \\
\hline Luhya & 57 (23.3) & 12 (14.5) & $45(26.8)$ & \\
\hline Luo & $131(38.9)$ & $40(45.3)$ & $91(36.3)$ & \\
\hline Others & 78 (23.9) & $23(21.8)$ & $55(24.8)$ & \\
\hline $\begin{array}{l}\text { Highest educational } \\
\text { level }\end{array}$ & & & & 0.0033 \\
\hline No education & $22(5.9)$ & $4(2.8)$ & $18(7.1)$ & \\
\hline Primary & $191(64.1)$ & $50(50.6)$ & $141(69.4)$ & \\
\hline $\begin{array}{l}\text { Secondary or } \\
\text { higher }\end{array}$ & $91(30.0)$ & 38 (46.6) & 53 (23.5) & \\
\hline Wealth index & & & & 0.0003 \\
\hline Low & $97(32.7)$ & $14(15.5)$ & 83 (39.5) & \\
\hline Middle & $48(14.8)$ & $11(11.1)$ & $37(16.2)$ & \\
\hline High & 159 (52.6) & $67(73.4)$ & $92(44.3)$ & \\
\hline Religion & & & & 0.745 \\
\hline Roman Catholic & $76(22.6)$ & $23(23.8)$ & $53(22.2)$ & \\
\hline $\begin{array}{l}\text { Protestant/other } \\
\text { Christian }\end{array}$ & $210(71.9)$ & $63(72.5)$ & 147 (71.6) & \\
\hline Others & $18(5.5)$ & $6(3.7)$ & $12(6.2)$ & \\
\hline \multicolumn{5}{|l|}{ Age (years) } \\
\hline $15-19$ & $24(7.0)$ & $3(2.9)$ & $21(8.7)$ & 0.3343 \\
\hline $20-24$ & $54(16.4)$ & $11(14.7)$ & $43(17.1)$ & \\
\hline $25-29$ & $63(22.9)$ & 23 (21.5) & 40 (23.4) & \\
\hline $30-34$ & $62(19.3)$ & 22 (26.9) & 40 (16.3) & \\
\hline $35-39$ & 45 (11.3) & $16(13.8)$ & $29(10.3)$ & \\
\hline $40-44$ & $31(16.2)$ & $9(11.2)$ & $22(18.1)$ & \\
\hline $45-49$ & $25(6.9)$ & $8(9.0)$ & $17(6.1)$ & \\
\hline \multicolumn{5}{|l|}{ Marital status } \\
\hline Married & $143(45.6)$ & 44 (51.8) & 99 (43.2) & 0.2967 \\
\hline Not married & $161(54.4)$ & 48 (48.2) & $113(56.8)$ & \\
\hline
\end{tabular}

Counts and percentages represent unweighted frequencies and weighted percentages of study population. $P$ value is derived from the Rao-Scott $\chi^{2}$ test. Percentages may not sum to 100 due to rounding. 

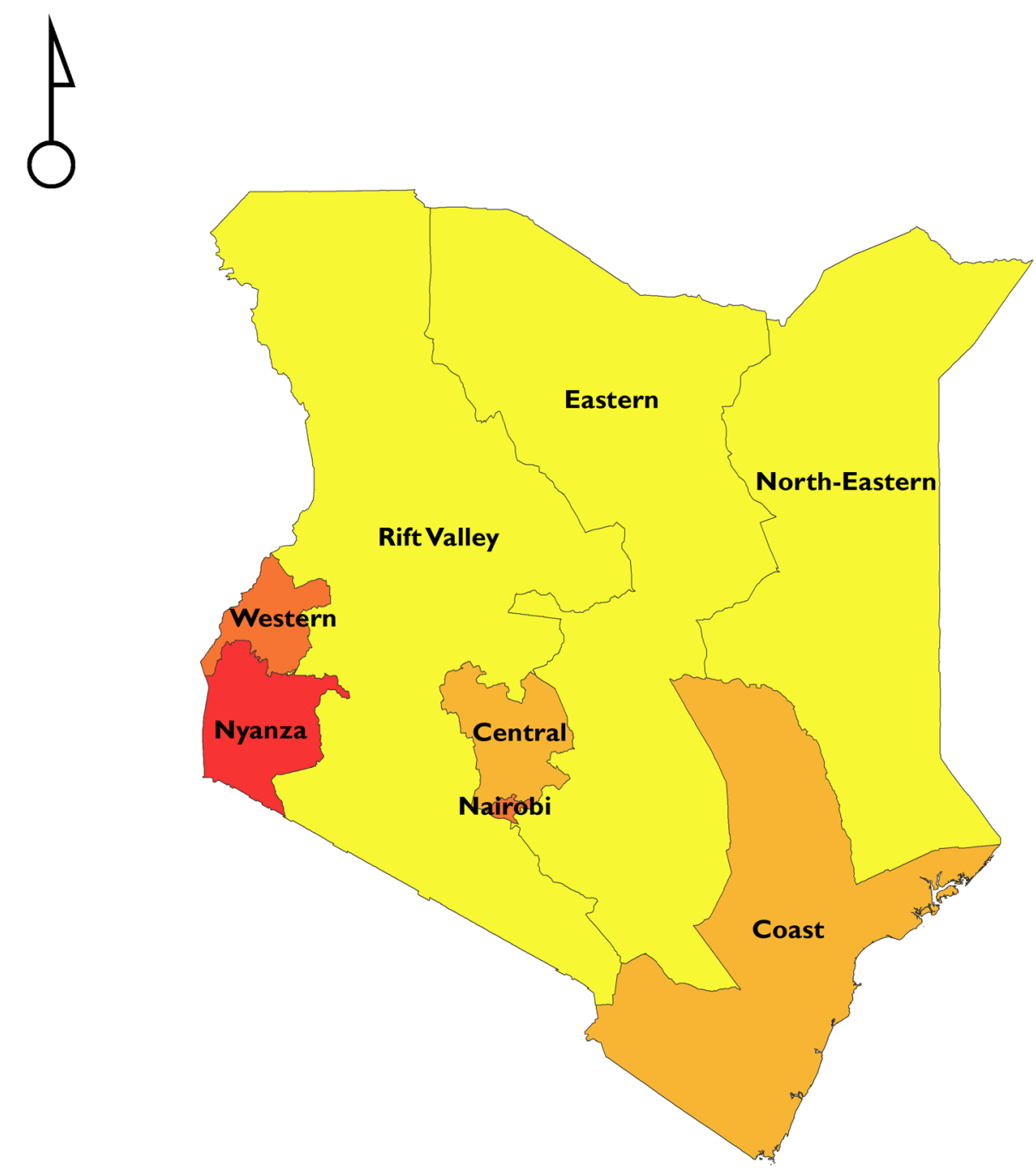

WLWHA Prevalence/100000

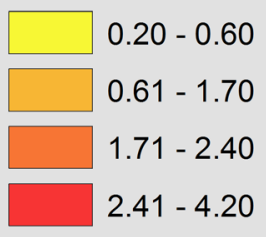

Figure 1 Prevalence map of WLWHA aged 15-49 years per 100000. WLWHA, women living with HIV/AIDS.

The Kenyan DHS is a nationally representative survey conducted every 5 years by Kenyan health agencies to assess the country's health status. The KDHS employed a stratified two-stage sample design by identifying 400 sampling units or clusters as identified by the Kenyan Population census and sampled households from all eligible households within each cluster. Respondents to the survey included men and women aged 15-54 years and 15-49 years, respectively. Data collected include indicators of fertility, reproductive health, maternal and child health, mortality, nutrition and self-reported health behaviours among adults.
We obtained data on three domains: demographics and general health (DGH), Global Positioning System (GPS) and deidentified HIV data to protect the privacy of participants. Data on HIV status was obtained after a written request to the DHS division of the USAID was granted. Records from the HIV and DGH datasets were linked by cluster, house number and line number. These were subsequently linked with the GPS data by cluster and region to compile the final data for analysis.

\section{Study population}

The source population consisted of 8444 women. Our initial study population included 318 women aged 
Table 2 Regression analysis showing ORs and 95\% Cls for the association of sociodemographic factors and contraceptive use among HIV-positive women in Kenya

\begin{tabular}{lll}
\hline Variables & COR $(95 \%$ Cl) & AOR $(95 \%$ CI) \\
\hline Region & & \\
\hline Nairobi & $2.22(0.92$ to 5.36$)$ & $0.74(0.17$ to 3.13$)$ \\
\hline Coast & $0.52(0.17$ to 1.61$)$ & $0.27(0.05$ to 1.55$)$ \\
\hline Rift Valley & $0.71(0.18$ to 2.80$)$ & $0.51(0.08$ to 3.47$)$ \\
\hline Others & $1.32(0.58$ to 3.03$)$ & $1.16(0.29$ to 4.70$)$ \\
\hline Western & $0.53(0.21$ to 1.31$)$ & $0.80(0.20$ to 3.20$)$ \\
\hline Nyanza & Reference $(1.0)$ & Reference $(1.0)$ \\
\hline Residence & & \\
\hline Rural & $0.55(0.26$ to 1.19$)$ & $1.04(0.36$ to 3.01$)$ \\
\hline Urban & Reference $(1.0)$ & Reference $(1.0)$ \\
\hline Ethnicity & & \\
\hline Kikuyu & $1.22(0.42$ to 3.59$)$ & $0.68(0.14$ to 3.27$)$ \\
\hline Luhya & $0.44(0.15$ to 1.26$)$ & $0.33(0.06$ to 1.75$)$ \\
\hline Others & $0.71(0.35$ to 1.45$)$ & $0.51(0.14$ to 1.87$)$ \\
\hline Luo & Reference $(1.0)$ & Reference $(1.0)$ \\
\hline
\end{tabular}

Highest

educational level

\begin{tabular}{|c|c|c|}
\hline No education & 0.20 (0.05 to 0.75$)$ & 0.60 (0.12 to 2.98$)$ \\
\hline Primary & 0.37 (0.17 to 0.81$)$ & $0.42(0.18$ to 0.98$)$ \\
\hline $\begin{array}{l}\text { Secondary or } \\
\text { higher }\end{array}$ & Reference (1.0) & Reference (1.0) \\
\hline \multicolumn{3}{|l|}{ Wealth index } \\
\hline Low & 0.24 (0.11 to 0.52$)$ & 0.17 (0.07 to 0.43$)$ \\
\hline Middle & 0.41 (0.17 to 1.01$)$ & 0.33 (0.11 to 0.98$)$ \\
\hline High & Reference (1.0) & Reference (1.0) \\
\hline \multicolumn{3}{|l|}{ Religion } \\
\hline $\begin{array}{l}\text { Protestant/other } \\
\text { Christian }\end{array}$ & 0.94 (0.47 to 1.91$)$ & 1.06 (0.48 to 2.37$)$ \\
\hline Others & 0.55 (0.12 to 2.47$)$ & $1.11(0.16$ to 7.75$)$ \\
\hline Roman Catholic & Reference (1.0) & Reference (1.0) \\
\hline $\mathrm{Age}^{*}$ & 1.08 (0.9 to 1.3$)$ & $1.22(0.99$ to 1.51$)$ \\
\hline \multicolumn{3}{|l|}{ Marital status } \\
\hline Not married & 0.71 (0.37 to 1.4$)$ & $0.57(0.29$ to 1.15$)$ \\
\hline Married & Reference (1.0) & Reference (1.0) \\
\hline
\end{tabular}

The AOR models include adjustment for age, marital status, region, residence, religion, ethnicity, education attainment and wealth index.

${ }^{*}$ Age was included as an ordinal variable.

AOR, adjusted OR; COR, crude OR.

15-49 years with a documented HIV positive result as determined by a laboratory test on dried blood spot samples conducted by the KDHS. We excluded women with incomplete data on study variables $(n=14)$. The final study population consisted of 304 HIV-positive women.

\section{Ethical approval}

In addition, we obtained permission by written request and subsequent approval from the DHS division of the USAID.

\section{Patient and public involvement (PPI)}

For this analysis, there was no PPI involvement; however, for the original project from which data was obtained, PPI participation was essential. ${ }^{17}$

\section{Study variables}

The outcome of interest was contraceptive use, and subjects were classified as using or not using contraceptives. The independent variables were sociodemographic characteristics. These sociodemographic characteristics included age in 5-year groups (15-19, 20-24, 25-29, 30-34, 35-39, 40-44 and 45-49 years), marital status (married or not married), region (Nairobi, Coast, Nyanza, Rift Valley, Western and others: North Eastern, Eastern and Central), residence (urban or rural), ethnicity (Kikuyu, Luhya, Luo or others: Embu, Kalenjin, Kamba, Kisii and Masai), highest educational level (no education, primary, secondary or higher), wealth index (low, middle or high) and religion (Roman Catholic, Protestant/other Christian denominations and other religious groups).

GPS coordinates for each respondent were included in our analysis to graphically represent the clustering of subjects. The DHS randomly displaced these coordinates by $2 \mathrm{~km}$ in the urban and $5 \mathrm{~km}$ in the rural zones, with $1 \%$ of the rural clusters further displaced by $10 \mathrm{~km}$ to protect the confidentiality of respondents.

\section{Statistical analysis}

Analysis was conducted using procedures for complex survey design, and sample weights were applied to all analysis. The characteristics of the study groups were described using unweighted frequencies and weighted percentages. Differences in the proportion of sociodemographic characteristics between contraceptive users and non-users were tested using Rao-Scott $\chi^{2}$ test. Crude ORs were computed by examining each sociodemographic variable with contraceptive use using weighted simple logistic regression models. All sociodemographic variables, age, marital status, region, residence, religion, ethnicity, education attainment and wealth index, were included in a weighted multiple logistic regression model to determine the sociodemographic factors independently associated with contraceptive use. Given our sample size and numerous categories within age, we included age as an ordinal variable in our multiple logistic regression model. ORs and their corresponding 95\% CIs were reported.

\section{Spatial analysis}

A prevalence map was constructed on the DHS dataset to illustrate the distribution of WLWHA in Kenya in ArcMap. The prevalence was calculated by dividing the numerator for each region (WLWHA) by denominator (total population per region). Hotspot Analysis (Getis-Ord Gi*) in 


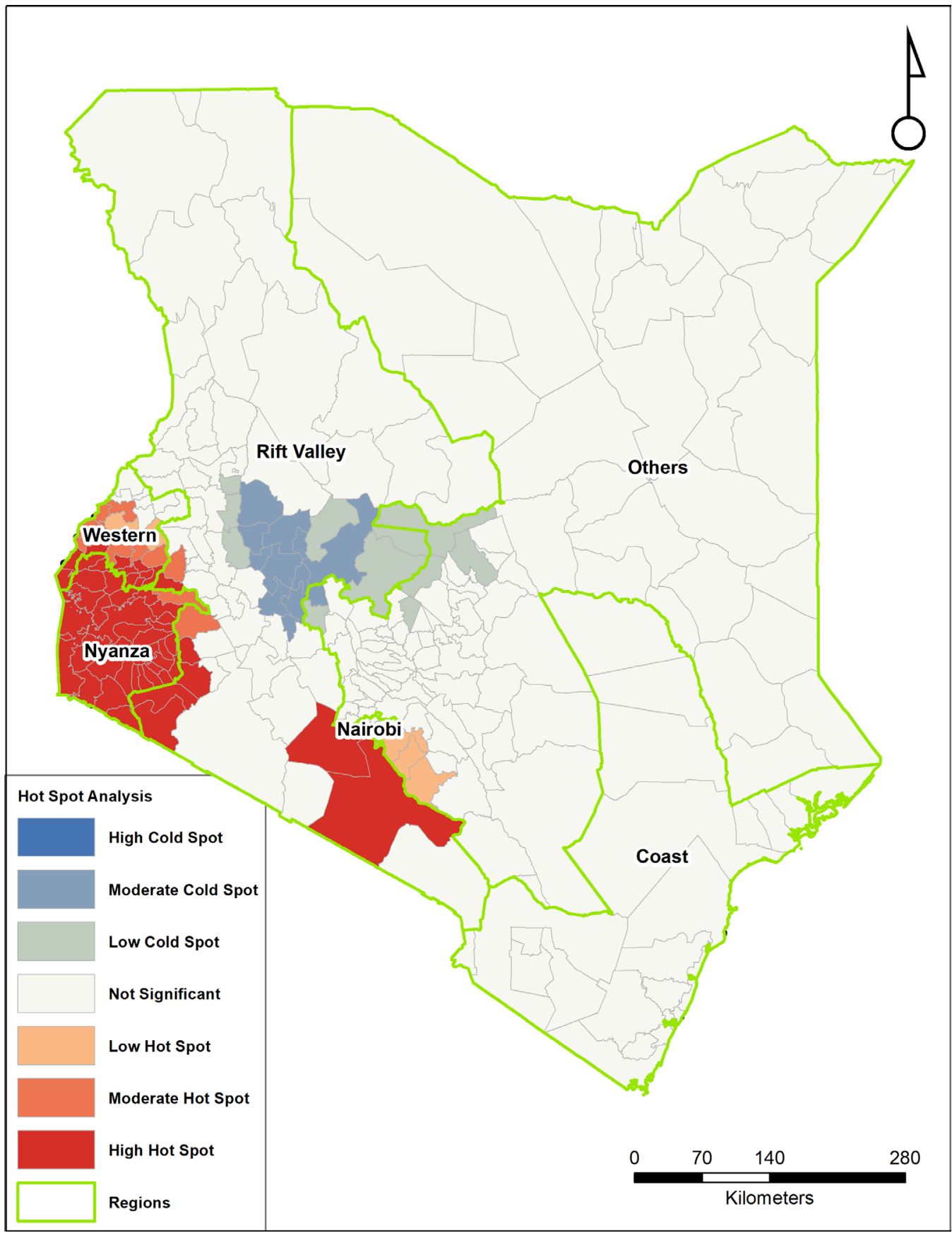

Figure 2 Hotspot analysis of contraceptive non-use among WLWHA in Kenya per region. WLWHA, women living with HIV/ AIDS.

ArcGIS was employed to identify geographic landscapes that have significant high clusters and areas with significant low clusters based on three levels of CI. The z-score and $p$ values parameters are indicators of statistical significance that enables the analyst to decide whether to accept or reject the null hypothesis. They also indicate whether the observed spatial clustering of high or low values is more pronounced than one would expect in a random distribution of those same values. A high z-score and small $p$ value $(\mathrm{p}<0.05)$ for a feature indicates a spatial clustering of high values. A low negative z-score and small $p$ value indicates a spatial clustering of low values. The higher the z-score, the more intense the clustering.
A z-score near zero indicates no apparent spatial clustering. ${ }^{18-21}$ The input feature class for the hotspot analysis was the non-contraceptive layer, while the fixed distance band allowed for each centroid to have a neighbour. However, Euclidean intersite distance method was used to measure distance between two straight georeferenced clusters.

High and low clustering tool (Getis-Ord General G) is an inferential statistic that is interpreted in the context of the null hypothesis. The null hypothesis for the General G statistics (no spatial clustering) is rejected when the $z$-score is very high and the $p$ value is low. Similarly, when the z-score is positive, it is interpreted as high values 


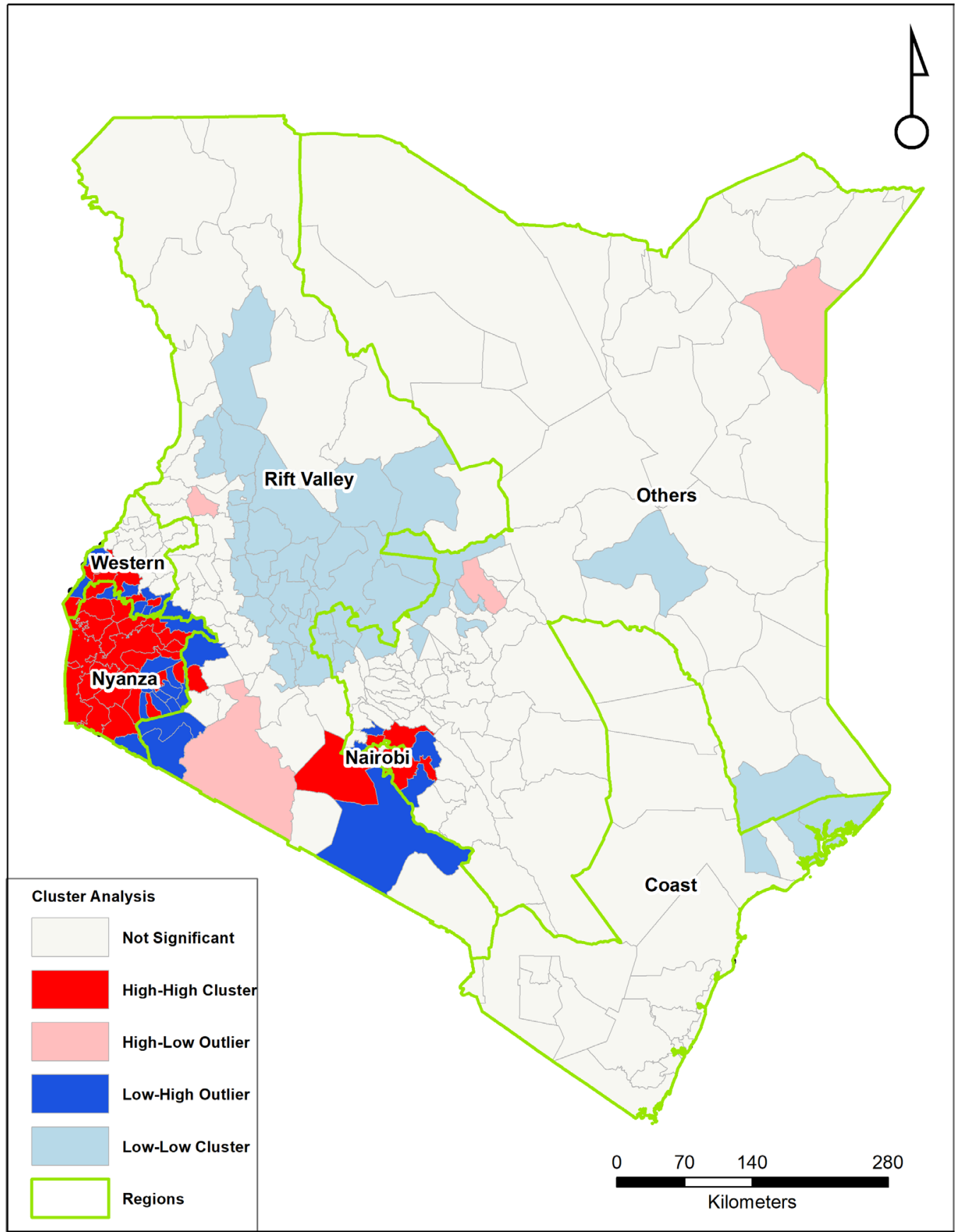

Figure 3 Cluster analysis of contraceptive non-use among WLWHA in Kenya per region. WLWHA, women living with HIV/ AIDS.

clustering within a georeferenced neighbourhood, and if the z-score is negative, it can be interpreted as clusters of low values within a study site. ${ }^{18-21}$ The methodology involves opening the Arc Toolbox, clicking on the spatial statistic tool and analysing pattern in ArcMap.

Also, the cluster and outlier tools were employed to identify cluster of features with similar values in magnitude and spatial outliers by creating a statistical algorithm for calculating a local Moran's I value, a z-score, a p value and a code representing the cluster type for each statistically significant feature. Large z-scores signify an intense clustering of high values $(\mathrm{HH})$ and a low z-score demonstrates more intense clustering of low values (LLs). ${ }^{18-20}$ The cluster/ outlier type field in Anselin's local Moran's Index distinguishes between a statistically significant cluster of high values $(\mathrm{HH})$, cluster of low values (LL), outlier in which a high value is surrounded primarily by low values (HL), and outlier in which a low value is surrounded primarily by high values $(\mathrm{LH}){ }^{22}$ Statistical significance was set at the 95\% CI, and no false discovery rate correction was applied to influence the critical $p$ values. ${ }^{19}$ Variables with $p$ values less than 0.05 were considered statistically significant.

\section{RESULTS}

The study population consisted of 304 HIV positive females, aged between 15 years and 49 years. Of these, 92 

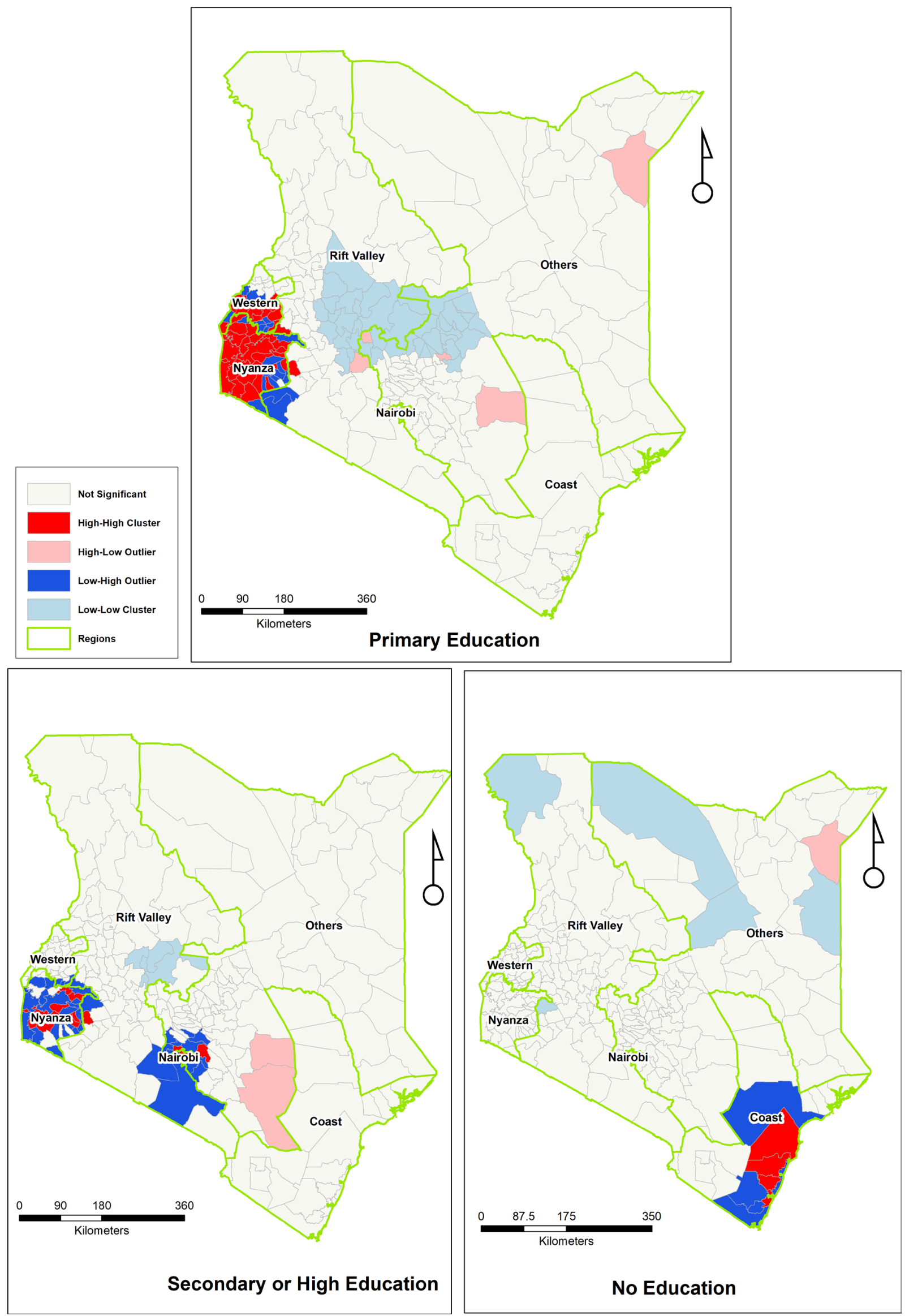

Figure 4 Cluster analysis of education on contraceptive non-use among WLWHA in Kenya. WLWHA, women living with HIV/ AIDS. 

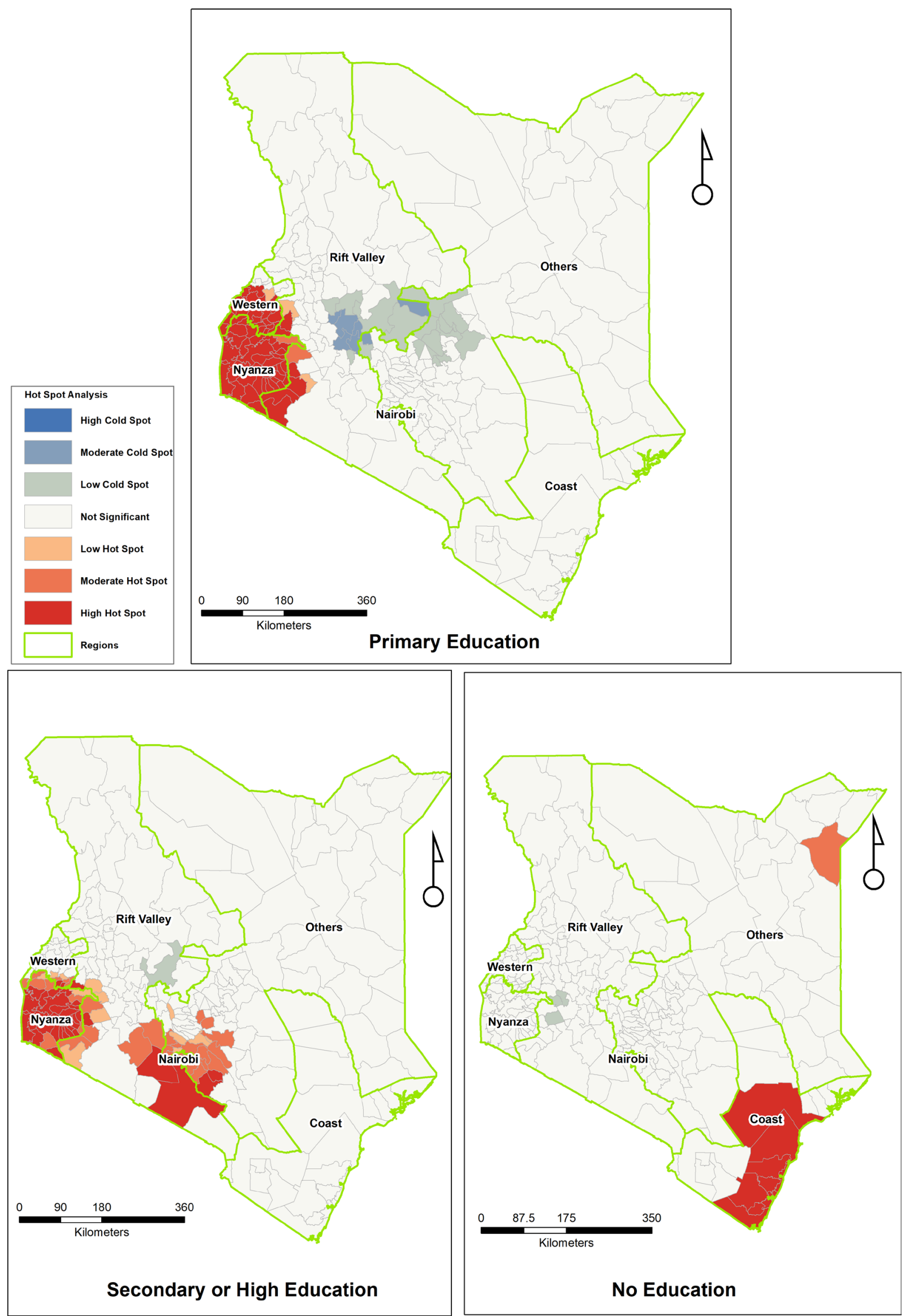

Figure 5 Hotspot analysis of education on contraceptive non-use among WLWHA in Kenya. WLWHA, women living with HIV/ AIDS. 
Table 3 Autocorrelation statistics of sociodemographic characteristics on non-contraceptive use among WLWHA in Kenya

\begin{tabular}{llll}
\hline Predictors & $\begin{array}{l}\text { Moran's } \\
\text { Index }\end{array}$ & Z-score & P value \\
\hline Wealth index & & & \\
Low income & 0.21 & 12.43 & $<0.00$ \\
Middle income & 0.12 & 6.80 & $<0.00$ \\
\hline High income & 0.10 & 5.62 & $<0.00$ \\
Highest educational level & & & \\
No education & 0.04 & 2.58 & 0.01 \\
\hline $\begin{array}{l}\text { Primary } \\
\text { Secondary or higher }\end{array}$ & 0.20 & 11.88 & 0.00 \\
\hline
\end{tabular}

$(30.3 \%)$ reported using contraceptives (table 1$)$. About $30 \%$ of the study population resided in urban areas, while $70 \%$ lived in the rural areas. Approximately $46 \%$ of women were married, and $46 \%$ of women were between 15 years and 29 years. Furthermore, $10.8 \%$ were from the Nairobi region, $5.4 \%$ from the Coast, $35.3 \%$ from Nyanza, $20.0 \%$ from Rift Valley, $12.5 \%$ from Western area and $15.9 \%$ from other regions. Most women were from the Luo ethnic group (38.9\%), followed by Luhya $(23.3 \%)$ and Kikuyu (13.9\%); approximately $17 \%$ of study subjects were from other ethnic groups. A majority of women were classified as high-income earners $(52.6 \%)$, while $14.8 \%$ and $32.7 \%$ were classified as middle-income and low-income earners, respectively. Approximately $5.9 \%$ of these women had no formal education, $64.1 \%$ attained primary education and $30 \%$ attained secondary or higher education. With respect to religion, $72 \%$ of women reported as Protestants or from other Christian denominations, 22.6\% were Catholics and $5.5 \%$ were from other religions.

Table 1 shows the distribution of sociodemographic characteristics across study groups. There were no statistical significant differences in the proportion of these characteristics except for educational attainment and wealth index. Among women who reported not using contraceptives, $7.1 \%$ had no formal education compared with $2.8 \%$ of women who used contraceptives. Conversely, women who used contraceptives were more educated than women who did not use any form of contraception $(46.6 \%$ vs $23.5 \%)$. These differences were statistically significant $(p=0.0033)$. Furthermore, approximately $39 \%$ of women who do not use contraceptives have a low wealth index compared with $15 \%$ of women who use contraceptives $(\mathrm{p}=0.0003)$.

Figure 1 is a prevalence map illustrating the distribution of WLWHA in different regions of Kenya per 100000 populations. Nyanza was observed to have the highest prevalence of women between the ages of 15-49 years living with HIV/AIDS (2.41-4.20/100 000 population) compared with Eastern, North Eastern and Rift Valley regions (0.20-0.60/100000 population).
Table 2 reports the crude and adjusted ORs of the association between sociodemographic factors and contraceptive use among Kenyan WLWHA. Consistent with results from table 1 , level of education and wealth index remained as independent predictors of contraceptive use in our adjusted models.

In univariate analyses, women without any primary education had $80 \%$ lower odds of using contraceptives compared with women with secondary or tertiary education $(\mathrm{OR}=0.2,95 \% \mathrm{CI} 0.05$ to 0.75$)$. However, this effect was substantially attenuated after controlling for other variables, including wealth index $(\mathrm{OR}=0.6,95 \%$ CI 0.12 to 2.98 ). Women with primary education only were approximately $58 \%$ less likely to use contraceptives ( $\mathrm{OR}=0.42,95 \%$ CI 0.18 to 0.98$)$ compared with women with secondary or higher education after adjusting for other sociodemographic characteristics.

Similarly, in univariate analyses, women with low wealth index were approximately $76 \%$ less likely to use contraception ( $\mathrm{OR}=0.24,95 \%$ CI 0.11 to 0.52 ) compared with women with high wealth index. This association persisted and increased slightly in magnitude after controlling for other variables $(\mathrm{OR}=0.17,95 \%$ CI 0.06 to 0.43 ). In a dose-response fashion, women classified as having a middle wealth index were $59 \%$ less likely to use contraceptives compared with women classified as having a high wealth index $(\mathrm{OR}=0.41,95 \% \mathrm{CI} 0.17$ to 1.02). After adjusting for other sociodemographic variables, the association increased slightly in magnitude and was marginally statistically significant $(\mathrm{OR}=0.33$, $95 \%$ CI 0.11 to 0.98 ).

Getis and Ord $\mathrm{Gi}^{*}$ analysis in figure 2 revealed hotspots for contraceptive non-use among WLWHA in Nyanza and Nairobi regions, while Rift Valley is a region with significant cold spots. Cluster analysis in figure 3 revealed high clusters of non-contraceptive use in WLWHA within localities of Nyanza and parts of Nairobi, whereas Rift Valley has low clusters of non-contraceptive use. Nevertheless, spatial outliers were important epidemographic features seen for Nyanza and Nairobi. Furthermore, figure 4 revealed high spatial clustering of contraceptive non-use among study participants with primary education in Nyanza, and mainly cluster outliers for other levels of education in different regions of Kenya. Figure 5 further demonstrates that Nyanza and Nairobi regions show significant hotspot for education and study participants had at least primary form of education.

Table 3 revealed a moderately high z-score $>2.56$ and small $\mathrm{p}$ values $<0.05$ for wealth index (high, middle and low) and educational level (no education, primary and secondary or higher). Therefore, we rejected the null hypothesis that there was no spatial clustering for the predictors of interest. However, the clustering tendencies for these variables as indicated by the Moran's Index is weak $(<0.30)$ for contraceptive non-use among WLWHA in Kenya. 


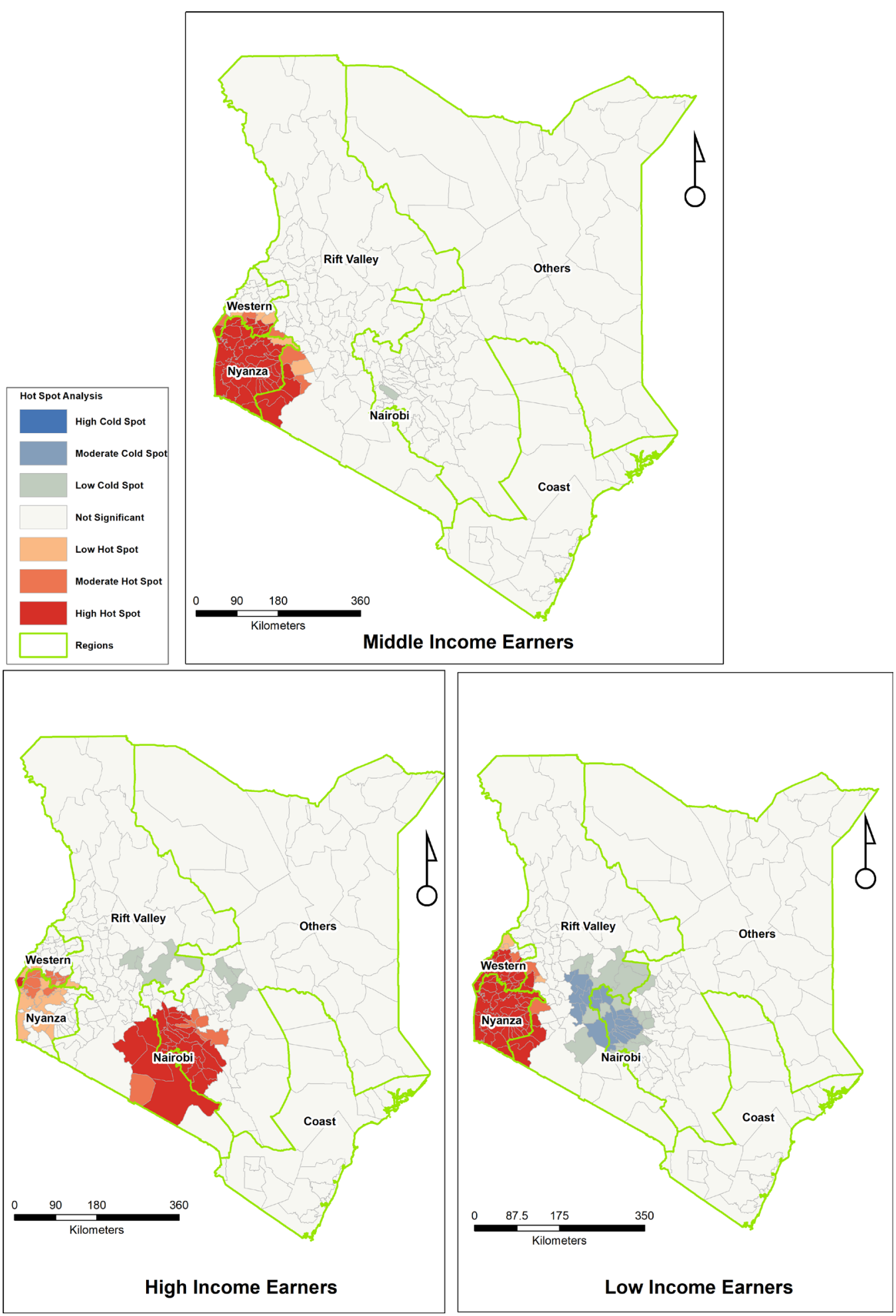

Figure 6 Hotspot analysis of Income on contraceptive non-use among WLWHA in Kenya. WLWHA, women living with HIV/ AIDS.

\section{DISCUSSION}

The objective of this study was to examine the relationship between contraceptive use and sociodemographic factors including the effect of clustering tendencies of these factors on contraceptive utilisation among WLWHA using spatial autocorrelation statistics. Findings from this study reveals wealth index and educational level to be significant sociodemographic predictors of contraceptive use. Women with low and middle wealth index were less likely to use contraceptives compared with women with high wealth index. This finding is consistent with previous studies in Mozambican and Malawian women where a lower use of modern contraceptives was found among women with low income. ${ }^{23}{ }^{24}$ Decreased use of 

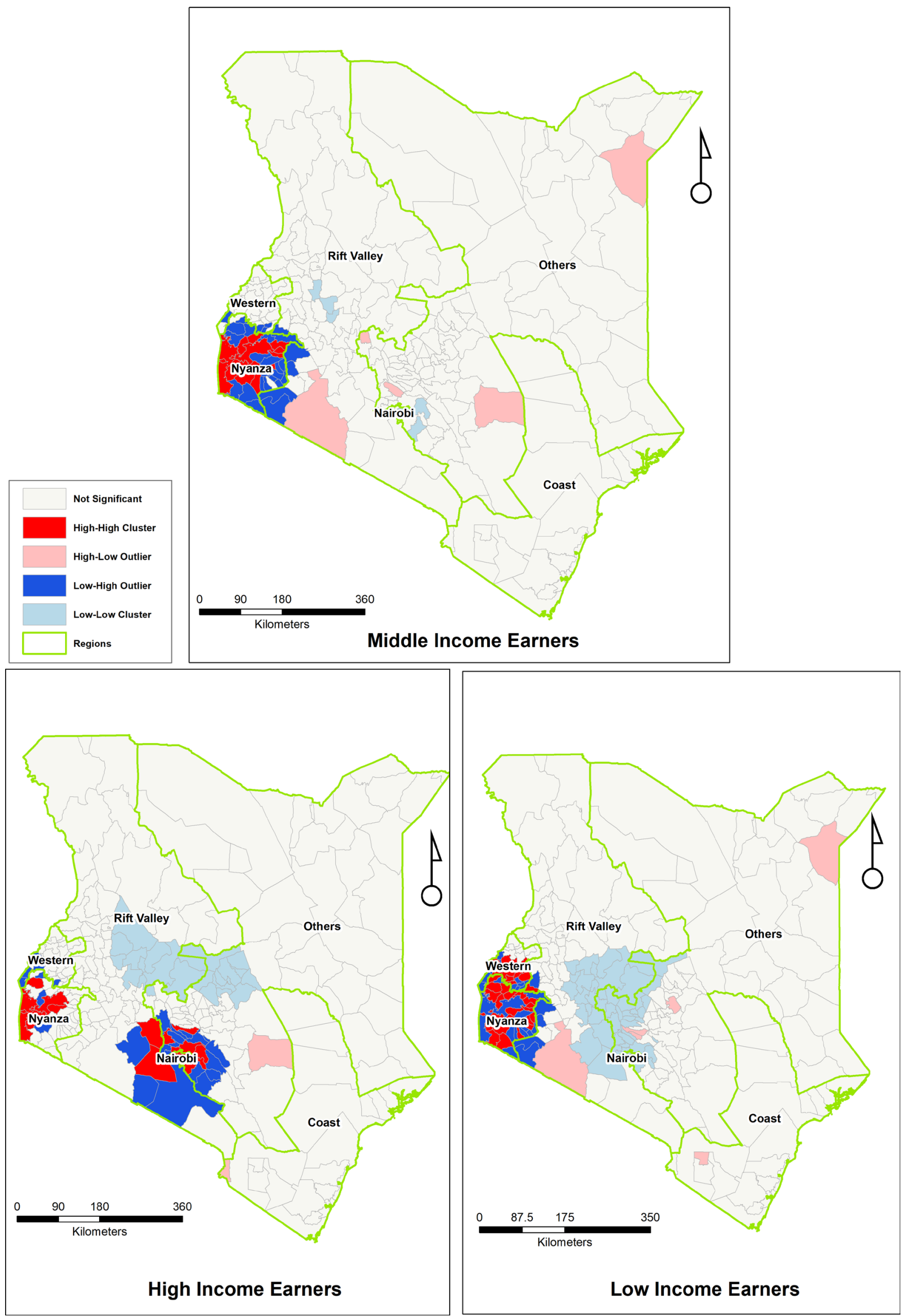

Figure 7 Cluster analysis of income on contraceptive non-use among WLWHA in Kenya. WLWHA, women living with HIV/ AIDS. 
contraceptives observed for these women might suggest lack of accessibility and affordability of contraceptives in relation to those with high income.

From our results, $74 \%$ of non-contraceptive users live in rural areas compared with $61 \%$ of contraceptive users in our study. Given that people who reside in poorer communities generally have a slower uptake of good health practices such as contraceptive use,${ }^{23}$ it is likely that the environmental influences on women with low wealth index might limit opportunities to access or afford contraceptives. This highlights a possible target for intervention by the Government of Kenya (GoK) through the provision of free or subsidised contraceptives for WLWHA, especially those living in rural areas with limited health facilities. Additionally, the Kenya Household Health Expenditure and Utilization Survey 2013 report stated that approximately $3 \%$ of Kenyans in the lowest wealth category have health insurance. ${ }^{25}$ Although the GoK waives the fee of services at government-owned hospitals, pharmacies and maternal care clinics, no programme explicitly targets WLWHA through the provision of low cost or free health insurance. ${ }^{2627}$ Consequently, the financial responsibility of purchasing prescription drugs and modern contraceptives falls on the patient that could ultimately be a barrier to access. Therefore, efforts to improve insurance coverage for WLWHA could improve accessibility by reducing the financial burden associated with purchasing effective modern contraceptives.

Another important finding was that women with primary education only had a lower likelihood of contraceptive use than those with secondary and higher education. Similar findings were reported in previous studies highlighting a greater likelihood of using contraception in women with secondary education or higher. ${ }^{6} 7112829$ This might not necessarily translate to lack of contraception awareness as studies have shown knowledge of contraception among women across all educational levels to be nearly universal and yet does not imply usage. ${ }^{82}$ Thus, our findings may reflect the association of lower educational attainment with established social determinants of health such as poverty and unemployment that could impede access to primary health facilities and subsequent contraceptive use. Furthermore, the influence of male decision making and power dynamics in couple relationships could also explain the association between low educational level and contraceptive use among WLWHA. A recent qualitative study of married men in the Nyanza province of Kenya found that men may disapprove the use of contraceptives by their spouses due to fear of losing their position of authority in the relationship and promotion of promiscuous behaviour. ${ }^{30}$ Given the importance of education to enhance women empowerment and autonomy, it is plausible that such power dynamics among low educated WLWHA may negatively influence contraceptive use. Also, some barriers such as fear of side effects, safety of method, improper use and fear of violence by partner if disclosed $^{329}$ have been reported in several studies and may explain the difference in contraceptive utilisation across educational levels. ${ }^{3} 472931$ Another study in Ethiopia reported that with increasing education, women tend to value the benefits that contraception offers, which enhances acceptability. ${ }^{8}$

Positive clustering tendencies were observed for levels of wealth index and education (see online supplementary file), which complemented the result obtained from the multiple logistic regression analysis. High clustering patterns with pockets of spatial outliers were seen for contraceptive non-use among study population in Nyanza and Nairobi. The high clustering pattern of contraceptive non-usage seen in Nyanza and Nairobi might be explained by the densely populated geographical pattern while cluster outliers (HL and LH) in Nyanza, Western and Nairobi may be explained by epidemiological connectivity and demographic changes. Hotspot analysis in figure 6 further explains the reason for the spatial outliers seen in figure 3 by demonstrating the presence of high hotspots for low-income and middle-income study participants not using contraceptives aggregating in Nyanza and high-income hot spots with contraceptive non-use in Nairobi. In addition, there are low cluster/ cold spot patterns seen in Rift Valley that may be due to more affluent study population living within those vicinities. Our findings validate other studies that reported low prevalence of contraceptive use in low-income WLWHA. Specifically, in a recent study conducted by Achana et al evaluating spatial patterns of sociodemographic determinants of contraceptive use in Ghanaian women, the authors reported higher levels of wealth to be predictive of contraceptive use. ${ }^{32}$ Harrington et al reported a low contraceptive uptake in Nyanza women accessing HIV care due to socioeconomic and demographic effects. ${ }^{4}$

Cluster and hotspot analysis on levels of education with contraceptive non-use revealed strong pattern of clustering with rim of spatial outliers among study populations in Nyanza, Nairobi and Coast regions as seen in figure 4. Nyanza region had a high spatial clustering of contraceptive non-use among study participants with primary education. This finding supports previous research that examined spatial patterns and factors associated with increased need for family planning and its corresponding decreased uptake in Nigerian women, as determined from the 2013 Nigeria Demographic Health Survey (DHS). Moreover, Oyeronke and colleagues showed that women with higher educational level had high use of contraception. ${ }^{33}$ Likewise, another study that examined spatial patterns of contraceptive use in the Democratic Republic of Congo reported that individuals with no education were less likely to use contraceptives. ${ }^{34}$ Also, the map of WLWHA not using contraceptives (figure 3) follows the same pattern as figure 4 . In other words, we were able to show with figures 3 and 4 that the study populations in regions of Kenya with low education had a higher concentration of non-contraceptive use. This important finding further elucidates the need for the incorporation of sexuality and reproductive health into school curriculum, as well as universal access to education for all women. 
This conclusion is consistent with other studies that have posited that sexuality education can improve reproductive health outcomes among adolescents. ${ }^{35} 36$

Hotspots analysis in figure 6 supports the findings from the cluster analysis in figure 7 that Nairobi and Rift Valley are cold spots for low-income earners (low values surrounded by low values) of the study population not using contraceptive. These spatial patterns further reinforce the stark socioeconomic inequality and wealth index inherent within districts of Nairobi and Rift Valley when compared with poor localities in Nyanza. There were also spatial outliers (HL and LH) clusters of low-income population living in Nyanza and Western region of Kenya not using contraceptives. This can be explained in terms of socioeconomics, gender norms and inequalities regarding safe and transactional sex. Gaps in contraception utilisation are attributable to a divide in family planning programmes and HIV care services. ${ }^{87}$ Low contraceptive utilisation in WLWHA necessitates urgent action to prevent series of health consequences; therefore, a more concerted effort between health service providers and public health professionals in ensuring that PMTCT programmes focus on HIV antiretroviral treatment and on provision, and counselling on contraceptive usage, particularly on the dual method (the use of a barrier method such as condom with an additional modern contraception), ${ }^{38}$ is essential, enabling these women to make an informed decision. ${ }^{88-40}$

The results of this analysis underscore the significant role of sociodemographic factors as determinants to contraception use and subsequent prevention of adverse health events when these factors are addressed and provides target areas where resources should be directed to improve population health. Targeted interventions, such as educational and health awareness campaigns should place more emphasis on women who are socioeconomically disadvantaged. Advancing women education and empowerment is a key strategy to address misconceptions about contraception. The provision of counselling services on contraceptive use, HIV and family planning programme integration are possible measures that could be adopted to increase contraceptive usage among WLWHA. Also, efforts towards attaining substantial increase in contraceptive use in WLWHA must ensure long-term commitment to improve sustainability, and stringent rules should be kept in place for adequate accountability of funding and logistics of reproductive health programmes especially in African countries. An increase in contraceptive use mediated by adequate and accessible contraception provision is required to protect the reproductive and health needs of these women and cater for their unmet needs, in line with sections (iii) and (iv) of SDG of United Nations. ${ }^{41}$

The DHS data used in this study represent nationally representative data. Despite this strength, the study design was cross-sectional, and therefore the direction of causality cannot be ascertained. Furthermore, data collected were based on self-report and could be prone to recall and social desirability bias. However, given similarities of our results with other published studies, we postulate that potential biases had limited impact on the study findings. In the spatial analysis, the evidence of clustering was most observed for regions with higher sample size; there was minimal variation in the distribution of the sample population with sparse concentration in the Eastern and North Eastern part of the country when compared with other regions. Therefore, the local Moran's Index used in our analysis could have overestimated or underestimated the effect of clustering tendencies for sociodemographic factors associated with contraceptive use. Similarly, this concern could have been responsible, at least in part, for the large chunk of insignificant clusters observed across some regions. Likewise, information and analysis derived from the DHS HIV-related dataset did not permit ascertainment of the potential epidemiological drivers of the significant spatial outliers observed in our spatial model.

Although the 2008-2009 DHS data used in this analysis are nearly a decade old, these data appear to represent the only publicly available data with HIV testing and GPS information for Kenya. Importantly, our results are consistent with conclusions from the Kenya AIDS Indicator Survey (KAIS) 2012 report, ${ }^{42}$ and results from this study based on currently obtainable data are presumed to still be largely reflective of current conditions, underscoring the urgent need of targeted intervention in hotspot areas. ${ }^{43}$ Numerous factors operating at various domains determine contraceptive use; however, our study examined the cluster patterns of these factors at the individual level. Future studies may focus on delineating the cluster patterns of structural and community level factors affecting contraceptive use among WLWHA.

\section{CONCLUSION}

These findings highlight the importance of extensive health education, counselling on safety of use of contraception, and improved access to contraception to mitigate the gap from social inequalities, including creation and enforcement of policies that protect and preserve women's health in sub-Saharan African countries, especially Kenya, which are pertinent in achieving the SDG of promoting accessible and affordable reproductive services, gender equality and women empowerment.

\section{Author affiliations}

${ }^{1}$ Department of Epidemiology and Biostatistics, College of Public Health, University of South Florida, Tampa, Florida, USA

${ }^{2}$ Department of Global Health, College of Public Health, University of South Florida, Tampa, Florida, USA

${ }^{3}$ Leidos Inc., Alexandria, Virginia, USA

Acknowledgements The authors would like to thank the United States Agency for International Development (USAID) for making available the Demographic and Health surveys (DHS) dataset used in this study. 
Contributors MLO conceptualised the study and was involved in all aspect of the analysis, findings and manuscript preparation. SA was involved in all aspects of spatial analysis and manuscript review. SO conducted the statistical analysis. NCE created the statistical analysis plan and reviewed all aspects of the statistical analysis. Al was involved in some aspects of the spatial analysis. KEK performed critical review, editing and study interpretation of the manuscript.

Funding The authors have not declared a specific grant for this research from any funding agency in the public, commercial or not-for-profit sectors.

Competing interests None declared.

Patient consent for publication Not required

Ethics approval The Kenya Medical Research Institute reviewed and approved this project.

Provenance and peer review Not commissioned; externally peer reviewed.

Data sharing statement № additional data are available.

Open access This is an open access article distributed in accordance with the Creative Commons Attribution Non Commercial (CC BY-NC 4.0) license, which permits others to distribute, remix, adapt, build upon this work non-commercially, and license their derivative works on different terms, provided the original work is properly cited, appropriate credit is given, any changes made indicated, and the use is non-commercial. See: http://creativecommons.org/licenses/by-nc/4.0/.

\section{REFERENCES}

1. Kharsany AB, Karim QA. HIV Infection and AIDS in Sub-Saharan Africa: Current Status, Challenges and Opportunities. Open AIDS J 2016;10:34-48.

2. Wekesa E, Coast E. Contraceptive need and use among individuals with HIV/AIDS living in the slums of Nairobi, Kenya. Int J Gynaecol Obstet 2015;130 Suppl 3:E31-E36.

3. Elfstrom KM, Stephenson R. The role of place in shaping contraceptive use among women in Africa. PLoS One 2012;7:e40670.

4. Harrington EK, Newmann SJ, Onono M, et al. Fertility intentions and interest in integrated family planning services among women living with HIV in Nyanza Province, Kenya: a qualitative study. Infect Dis Obstet Gynecol 2012;2012:1-8.

5. Joint United Nations Programme on HIV and AIDS. AIDS epidemic update. Country fact sheets. 2016 http://www.unaids.org/en/ regionscountries/countries/kenya/ (accessed 20 Jul 2017).

6. Shehu A, Joshua I, Umar Z. Knowledge of contraception and contraceptive choices among human immunodeficiency viruspositive women attending antiretroviral clinics in Zaria, Nigeria. SubSaharan African Journal of Medicine 2016;3:84-90.

7. Melaku YA, Zeleke EG. Contraceptive utilization and associated factors among HIV positive women on chronic follow up care in Tigray Region, Northern Ethiopia: a cross sectional study. PLoS One 2014;9:e94682.

8. Berhane $\mathrm{Y}$, Berhe $\mathrm{H}$, Abera GB, et al. Utilization of Modern Contraceptives among HIV Positive Reproductive Age Women in Tigray, Ethiopia: A Cross Sectional Study. Isrn Aids 2013;2013:1-8.

9. Sirengo M, Muthoni L, Kellogg TA, et al. Mother-to-child transmission of HIV in Kenya: results from a nationally representative study. $J$ Acquir Immune Defic Syndr 2014;66 Suppl 1(Suppl 1):S66-S74.

10. Stover J, Brown T, Marston M. Updates to the Spectrum/Estimation and Projection Package (EPP) model to estimate HIV trends for adults and children. Sex Transm Infect 2012;88 Suppl 2(Suppl 2):i11-i16.

11. Kalipeni E, Zulu L. Using GIS to model and forecast HIV/AIDS Rates in Africa, 1986-2010. The Professional Geographer 2008;60-33-53.

12. Messina JP, Emch M, Muwonga J, et al. Spatial and socio-behavioral patterns of HIV prevalence in the Democratic Republic of Congo. Soc Sci Med 2010;71:1428-35.

13. Tanser F, Lesueur D, Solarsh G, et al. HIV heterogeneity and proximity of homestead to roads in rural South Africa: an exploration using a geographical information system. Trop Med Int Health 2000;5:40-6.

14. Cuadros DF, Awad SF, Abu-Raddad LJ. Mapping HIV clustering: a strategy for identifying populations at high risk of HIV infection in sub-Saharan Africa. Int J Health Geogr 2013;12:28.

15. Wand H, Ramjee G. Targeting the hotspots: investigating spatial and demographic variations in HIV infection in small communities in South Africa. J Int AIDS Soc 2010;13:41.

16. Tanser F, Bärnighausen T, Cooke GS, et al. Localized spatial clustering of HIV infections in a widely disseminated rural South African epidemic. Int J Epidemiol 2009;38:1008-16.
17. Demographic Health Survey Kenya Statistical Service. Kenya multiple indicator cluster survey with an enhanced HIV/AIDS Module and Biomarker. 2008-2009 http://dhsprogram.com/what-we-do/ survey/survey-display-300.cfm (accessed $10 \mathrm{Jul} 2017$ ).

18. Anselin L. Local Indicators of Spatial Association-LISA. Geogr Anal 1995;27:93-115.

19. Djukpen RO. Mapping the HIV/AIDS epidemic in Nigeria using exploratory spatial data analysis. GeoJournal 2012;77-555-69.

20. Alao S, Mati K, Jacob B. Differentiating non-homoscedasticity and geospatially extreme outliers for urban and rural landscape dataset using pearson's product moment correlation coefficients for quantitating clustering tendencies in non- vaccinated measles populations in nigeria. Journal of Remote Sensing \& GIS 2016;05:185.

21. Stanley N, Alao S, Jacob B. Quantitating Non-Zero Autocorrelation to determine moran's I coefficients for mapping clustering tendencies of fast food restaurants in lower SES neighborhoods in hillsborough county, Florida. J Remote Sensing \& GIS 2016;05:179.

22. Mitchel A. The ESRI Guide to GIS analysis, Volume 2: Spatial measurements and statistics. Esri Press 2005.

23. Dias JG, de Oliveira IT. Multilevel effects of wealth on women's contraceptive use in Mozambique. PLoS One 2015;10:e0121758.

24. Adebowale SA, Adedini SA, Ibisomi LD, et al. Differential effect of wealth quintile on modern contraceptive use and fertility: evidence from Malawian women. BMC Womens Health 2014;14:40.

25. Ministry of Health, Government of Kenya. 2013 Kenya Household Health Expenditure and Utilization Survey. Nairobi. Kenya: Ministry of Health, 2014. https://www.healthpolicyproject.com/pubs/745_ KHHUESReportJanuary.pdf. (accessed 28 Sep 2018).

26. Chuma J, Maina T. Free Maternal Care and Removal of User Fees at Primary-Level Facilities in Kenya: Monitoring the Implementation and Impact-Baseline Report. Washington, DC: Health Policy Project, Futures Group, 2013. https://www.healthpolicyproject.com/pubs/ 400_KenyaUserFeesBaselineReportFINAL.pdf. (accessed $30 \mathrm{Sep}$ 2018).

27. Zollmann J, Ravishankar N. Struggling to thrive: How Kenya's low-income families (try to) pay for healthcare. Nairobi, Kenya: FSD Kenya, 2016. https://s3-eu-central-1.amazonaws.com/fsd-circle/wpcontent/uploads/2016/03/30093042/16-03-22-Struggling-to-ThriveReport.pdf. (accessed 28 September, 2018).

28. Goggin K, Mindry D, Beyeza-Kashesya J, et al. "Our hands are tied up": current state of safer conception services suggests the need for an integrated care model. Health Care Women Int 2014;35(79):990-1009.

29. Ochako R, Mbondo M, Aloo S, et al. Barriers to modern contraceptive methods uptake among young women in Kenya: a qualitative study. BMC Public Health 2015;15:118.

30. Withers M, Dworkin SL, Zakaras JM, et al. 'Women now wear trousers': men's perceptions of family planning in the context of changing gender relations in western Kenya. Cult Health Sex 2015;17:1132-46.

31. Obare F, van der Kwaak A, Birungi $H$. Factors associated with unintended pregnancy, poor birth outcomes and post-partum contraceptive use among HIV-positive female adolescents in Kenya. BMC Womens Health 2012;12:34

32. Achana FS, Bawah AA, Jackson EF, et al. Spatial and sociodemographic determinants of contraceptive use in the Upper East region of Ghana. Reprod Health 2015;12:29.

33. Oyeronke Alaba O, Olaomi JO, Olubusoye OE. Spatial pattern and determinants of unmet need of family planning in Nigeria. South African Family Practice 2015;57:306-12.

34. Kandala NB, Lukumu FK, Mantempa JN, et al. Disparities in modern contraception use among women in the Democratic Republic of Congo: a cross-sectional spatial analysis of provincial variations based on household survey data. J Biosoc Sci 2015;47:345-62.

35. Sidze E, Stillman M, Keogh S, et al. From paper to practice: Sexuality education policies and their implementation in Kenya. New York: Guttmacher Institute, 2017. https://www.guttmacher.org/report/ sexuality-education-kenya. (accessed 28 Sep 2018).

36. Duflo E, Dupas P, Kremer M. Education, HIV, and Early Fertility: Experimental Evidence from Kenya. Am Econ Rev 2015;105:2757-97.

37. Worke MD, Bezabih LM, Woldetasdik MA. Utilization of contraception among sexually active HIV positive women attending art clinic in University of Gondar Hospital: a hospital based cross-sectional study. BMC Womens Health 2016;16:67

38. Ajao KO, Osho PO, Koledoye V, et al. Factors influencing condom use among people living with HIV/AIDS attending clinics at state specialist hospital, Akure, Ondo State, Nigeria. Gynecol Obstet $2014 ; 4(254$. 
39. Raifman J, Chetty T, Tanser F, et al. Preventing unintended pregnancy and HIV transmission: effects of the HIV treatment cascade on contraceptive use and choice in rural KwaZulu-Natal. J Acquir Immune Defic Syndr 2014;67 Suppl 4(Suppl 4):S218-S27.

40. World Health Organization. Sexual and reproductive health of women living with HIV/AIDS. Guidelines on care, treatment and support for women living with HIV/AIDS and their children in resourceconstrained settings. 2017 http://www.who.int/hiv/pub/guidelines/ rhr/en/ (accessed 20 Jul 2017).

41. Nations U. Transforming our world: The 2030 agenda for sustainable development. New York (NY): United Nations, 2015. https://sustaina bledevelopment.un.org/post2015/transformingourworld. (accessed 30 Jul 2017).

42. National AIDS and STI Control Programme (NASCOP), Kenya. Kenya AIDS Indicator Survey 2012: Final Report. Nairobi, NASCOP. 2014 https://nacc.or.ke/wp-content/uploads/2015/10/KAIS-2012.pdf (accessed 29 Sep 2018).

43. Maina WK, Kim AA, Rutherford GW, et al. Kenya AIDS Indicator Surveys 2007 and 2012: implications for public health policies for HIV prevention and treatment. J Acquir Immune Defic Syndr 2014;66 Suppl 1(Suppl 1):S130-S37. 